\title{
Spatial Variability of Small-leaved Linden (Tilia cordata Mill.) Leaf Blade
}

\author{
Sergey G. Baranov 1,*, Igor E. Zykov², Elena Yu. Poloskova³, Irina N. Lipponen³, Oxana A. \\ Goncharova $^{3}$, and Darya D. Kuznetsova ${ }^{2}$ \\ ${ }^{1}$ Vladimir State University named after A.G. and N.G. Stoletov, Gor'kogo, 79, 600005 Russian Federation \\ ${ }^{2}$ State Humanitarian Technological University, 22, Zelenaya Street, Orekhovo-Zuevo, 142611, Russian \\ Federation \\ ${ }^{3}$ Polar-alpine botanical garden, Murmansk region, Kirovsk, 184209, Russian Federation
}

\begin{abstract}
The features of asymmetry and shape of small-leaved linden leaf blades (Tilia cordata Mill.) on the Kola Peninsula (Murmansk region, Kirovsk) and in the middle part of Russia (Moscow region, Orekhovo-Zuevo) were studied. The size of leaf blades in the northern population (Murmansk oblast) was significantly smaller $(p<0.0001)$. Five linear traits had non-directional fluctuating asymmetry (FA). The method of geometric morphometrics showed a higher variability of leaf shape in the northern population compared to the southern one. Leaves differed in shape upon re-collection, and the leaf $\times$ side factor interaction showed the presence of FA in both populations (Goodall's $F$ criterion in the northern population was 31.7 ; in the southern $-92.3 ; p$ $<0.0001)$. A high value of directional asymmetry was noted in the population on the Kola Peninsula $(p<0.0001)$. The asymmetry of the shape did not depend on size of the leaf blades. According to linear features, plastic variability, especially in the northern population, strongly correlated with fluctuation variability $(r=0.81-0.82 ; p<0.05)$. The obtained data allows us to conclude that method of geometric morphometrics was more complex in determining the stability of development. FA was higher in the southern population, while directional asymmetry with a weak expropriation of FA was higher in the northern population. High latitude did not affect the decrease in developmental stability in terms of FA, but led to a decrease in the area of leaf blades with directional asymmetry.
\end{abstract}

\section{Introduction}

Introduction and acclimatization of wild and cultivated plant species requires a thorough study of their adaptive characteristics. In the last decade, in-depth studies of anatomical, physiological properties [1], biochemical parameters [2-3] and plant morphology [4-5] have been carried out. Results of the variability of genotypic and phenotypic properties studying depending on the area were obtained using the example of some tree species [6-9]. A general overview of climatic variability is being formed: with an increase in the latitude of the area, the width, area of the leaf blade and the metabolic rate decrease. For example, the sizes of leaf

\footnotetext{
* Corresponding author: bar.serg58@gmail.com
} 
blades and their asymmetry were studied under different conditions and data was obtained on an increase in asymmetry and a decrease in the size of leaf blades in Mountain birch (Betula pubescens var. pumila (L.) Govaerts) on the Kola Peninsula [10-13].

The asymmetry of leaf plates includes two types of asymmetry - fluctuating (FA) and directional asymmetry (DA), which are determined by both environment and genetic causes. FA is a slight and non-directional deviation from strict symmetry, without admixture of directional asymmetry. FA indices have long been used to determine the stability of plants population development, including species of Tilia genus [14-16].

Discussion of genotypic and genetic bases of developmental stability continues. Decomposition of variance components assumes the separate consideration of epistatic and epigenetic properties. It is interesting to search for elements of a purely ecological effect on the biochemical homeostasis of plants. Based on the linear signs of leaf blades, results were obtained on the effect of atmospheric and soil pollutants in urbanized areas on an increase in FA (decrease in developmental sustainability) [17-18]. Less is known about the impact of geographic range on developmental stability.

Plastic variability (PI) of the size of morphological characters is often associated with asymmetry. If there is such a correlation, then the increase in FA is explained by an increase in the size of characters, but not by deviation in developmental stability [19].

In previous study, a cold summer (2017) caused a decrease in the size of leaf blades with an increase in FA, which we explained by morphological adaptation, while plastic variability did not correlate with size of the trait. In this work, we studied morphological properties of the small-leaved linden (Tilia cordata Mill.) leaf blade in two populations - northern (Kola Peninsula) and in central Russia (Moscow region). Tasks of the work included:

a) Testing relationship between PI and FA in two geographically remote populations of small-leaved linden;

b) Obtaining an answer to the question whether the climatic factor influenced the asymmetry and shape of the leaf blades.

Working hypothesis assumed a statistically significant effect of climate influence on the asymmetry and shape of the leaf blades

\section{Site characteristics and sampling}

The control site represented population in the city of Orekhovo-Zuevo (Moscow region) on the territory of State Humanitarian and Technological University (GSTU) with coordinates $55^{\circ} 47^{\prime \prime} 31^{\prime} \mathrm{N}$; $38^{\circ} 56^{\prime \prime} 14^{\prime} \mathrm{E}$. The average air temperature in this part of Russia is $18-20^{\circ} \mathrm{C}$ in summer, $-15-20^{\circ} \mathrm{C}$ in winter, relief height is $132 \mathrm{~m}$.

The experimental population was a group of trees in the nursery of the Polar-Alpine Botanical Garden (PABG) in Murmansk region with coordinates $67^{\circ} 36^{\prime \prime} 51$ 'N; $33^{\circ} 40^{\prime \prime} 18$ 'E and with a relief height of $387 \mathrm{~m}$. This collection site is outside the natural range of smallleaved linden. Summers are cool and short, with an average temperature of $11-14^{\circ} \mathrm{C}$, in winter from -11 to $-14^{\circ} \mathrm{C}$ with an annual rainfall of 450 to $560 \mathrm{~mm}$. The collection of leaf plates was carried out 2 times with a break of 1.5-2 weeks, 5 leaf plates from each of ten trees evenly from the lower part of the crown; a total of 200 leaf blades were examined. Medium-sized leaves were collected from selected trees using standard techniques. The latitudinal zonation and high relief on the Kola Peninsula determined the late phenodata of the appearance of leaves and the beginning of flowering in comparison with central Russia. 


\section{Methods}

\subsection{Sample preparation}

After collection, the leaf plates were air-dried, placed in a paper press for final drying, and then scanned. The population assumed as an experimental unit of measurement, since the sampling was carried out twice. Five linear (metric) traits were measured [16], the biggest one is the width of half of the leaf blade, which is often used in such studies. Other traits were the segments of the veins branch. It is known that linear characters are heterogeneous in terms of variance heterogeneity, which makes insights to explain the nature of phenotypic variability.

\subsection{Descriptive statistics of metric traits}

The main characteristics of samples $(\mathrm{R}-\mathrm{L})$ descriptive statistics were evaluated, where $\mathrm{R}$ and $\mathrm{L}$ are the values of the right and left metric traits, as well as the presence of directional asymmetry and the normality (K-S test) of the distribution of fluctuating asymmetry, found by the formula $\mathrm{FA}=|\mathrm{R}-\mathrm{L}| /(\mathrm{R}+\mathrm{L})$.

The correlation coefficient was found between: a) the FA of all traits; b) the value $(\mathrm{R}+\mathrm{L})$ / 2 , that is, the value of the trait, and FA (the allometric relationship "leaf size - FA"). The plastic variability (PL), as a variation of metric characteristics of leaf on a tree, was determined by the formula: $\mathrm{PL}=1-(\mathrm{x} / \mathrm{X})$, where $\mathrm{x}$ and $\mathrm{X}$ is the minimum and maximum values of the trait, respectively. All measurements were processed in the STATISTICA 10 (StatSoft Ink).

\subsection{Method of geometric morphometrics}

The main advantage of this method is that it allows us to evaluate the asymmetry based on the shape of the entire plate, not on difference in the values of bilateral traits, which vary in the heterogeneity of the variance. The second advantage and convenience of the method is that the standard for comparing samples is the averaged consensus - the shape obtained after averaging all leaf samples. Finally, the third merit is in normalization of dimensions called Procrustes distances, which are built according to coordinates of the labels (landmarks) applied and reflect the deviation from the symmetric consensus.

50 landmarks along the contour of the plate was used and a common file was created (TPS software package; Rholf, 2014). For Procrustes analysis of variance the MorphoJ software package was used (Klingenberg, 2019). Statistical significance was evaluated at 95\%. The regression dependence FA - value of the consensus was defined. Influence of the population location, factor of leaf blades collection and their individual variability, both on the shape of the leaf plate and on its asymmetry was also determined. As previous studies have shown, the photographing error is extremely small, therefore, the image was acquired once, and the labeling with subsequent processing was carried out twice. The procedure for applying true landmarks of the first type was carried out with the splitting of the entire contour into equal segments, and is described in detail in previous works [20-21].

\section{Results and discussion}

\subsection{Descriptive statistics}

Sizes of all five traits were smaller in the northern population $(1.19 \mathrm{~cm}$ compared to the southern $-3.87 \mathrm{~cm}$, with an average standard deviation of 0.21 and 1.39 , respectively; $p<<$ $0.05)$, i.e., leaf blades on The Kola Peninsula were about half size of leaves from the Moscow 
region. The largest variance was found in the sample $(\mathrm{R}-\mathrm{L})$ in the third trait (GGTU). T-test indicated no difference between right and left sides ( $p>0.05$; table 1).

Table 1. Statistics $(\mathrm{R}-\mathrm{L})$ and FA

\begin{tabular}{|c|c|c|c|c|c|c|c|c|c|c|}
\hline \multirow{2}{*}{ Sample } & \multirow{2}{*}{ Trait, № } & \multicolumn{6}{|c|}{$(\mathbf{R}-\mathbf{L})$} & \multicolumn{3}{|c|}{ FA } \\
\hline & & Mean & St.error, m & Varaince, $\sigma$ & $t$ - test, $t$ & Skue, $\lambda$ & Kurtosis, $\gamma$ & FA mean & test $\mathrm{K}-\mathrm{S}, p$ & Varaince, $\sigma$ \\
\hline \multirow{5}{*}{ PABG } & 1 & -0.029 & 0.023 & 0.055 & 0.491 & -1.606 & 7.260 & 0.036 & $<0.01$ & 0.002 \\
\hline & 2 & 0.014 & 0.028 & 0.080 & 0.727 & 2.433 & 20.392 & 0.068 & $<0.01$ & 0.006 \\
\hline & 3 & 0.013 & 0.018 & 0.033 & 0.657 & -0.958 & 3.668 & 0.080 & $<0.20$ & 0.004 \\
\hline & 4 & 0.003 & 0.018 & 0.031 & 0.935 & -0.075 & 1.299 & 0.067 & $<0.01$ & 0.006 \\
\hline & 5 & -0.007 & 0.012 & 0.014 & 0.732 & -0.479 & 0.470 & 0.048 & $<0.05$ & 0.002 \\
\hline \multirow{5}{*}{ GGTU } & 1 & 0.055 & 0.025 & 0.063 & 0.100 & 0.037 & -0.267 & 0.027 & $<0.05$ & 0.000 \\
\hline & 2 & 0.006 & 0.029 & 0.083 & 0.915 & -0.662 & 1.907 & 0.069 & $>0.20$ & 0,003 \\
\hline & 3 & -0.065 & 0.156 & 2.445 & 0.744 & -1.773 & 23.424 & 0.114 & $<0.01$ & 0.023 \\
\hline & 4 & -0.002 & 0.160 & 0.055 & 0.340 & -0.186 & -0.081 & 0.064 & $<0.01$ & 0.003 \\
\hline & 5 & -0.127 & 0.144 & 2.068 & 0.630 & -2.428 & 29.674 & 0.095 & $<0.01$ & 0.017 \\
\hline
\end{tabular}

Thus, the direction of asymmetry in dimensional bilateral traits was not found. In terms of size, the right half of leaf blades prevailed, which is common for the right-sided spiral asymmetry in the arrangement of branches along the tree trunk. The largest deviation in the asymmetry of distribution (skew lambda more than two) was noted in second trait in PABG and in fifth trait in GGTU. The highest kurtosis values (20.39 and 29.68) were obtained for these traits, which influenced the corresponding value of fluctuating asymmetry. It was relatively high -0.068 and 0.095 , respectively. These variables characterized the highest variance of fluctuating asymmetry (0.006 and 0.017$)$. Notably the FA variables had predominantly nonparametric distribution (except trait № 2, GGTU, $p>0.2$; K-S-test), that accordingly, did not allow comparing the FA mean values. There was no difference in the mean integral FA values (Wilks $p>0.05$ ). Thus, despite the difference in leaf sizes, they did not differ in asymmetry. The population difference was only in traits 3 and 5 (table 2 ).

Table 2. Population difference FA in traits (One-Way ANOVA)

\begin{tabular}{|c|c|c|c|c|c|c|}
\hline \multirow{2}{*}{ Trait № } & \multirow{2}{*}{ SS } & \multicolumn{2}{|c|}{ MS } & \multirow{2}{*}{$\boldsymbol{t}$-value } & $\boldsymbol{d}$ & $\boldsymbol{p}$ \\
\cline { 3 - 6 } & & GGTU & PABG & & & \\
\hline 1 & 0.004 & 0.027 & 0.036 & -1.753 & 198 & 0.081 \\
\hline 2 & 0.000 & 0.069 & 0.068 & 0.084 & 198 & 0.933 \\
\hline 3 & 0.057 & 0.114 & 0.080 & 2.055 & 198 & 0.041 \\
\hline 4 & 0.000 & 0.064 & 0.067 & -0.310 & 198 & 0.757 \\
\hline 5 & 0.108 & 0.095 & 0.048 & 3.376 & 198 & 0.001 \\
\hline
\end{tabular}

Notes: SS - sum square; mean MS - mean square; $d f$ - degree of freedom; $p$ - probability level

The table shows just the nominal difference in the asymmetry of features, since most of the samples $|\mathrm{R}-\mathrm{L}| /(\mathrm{R}+\mathrm{L})$ did not have the normal distribution required for the $t$-test. 


\subsection{Correlations}

Correlation between the FA of traits, as well as between their value and the FA was defined using Spearman nonparametric coefficient $r$. There was no correlation between the FA values for traits, except for a weak correlation between the FA values for traits 2 and 5 in the PABG population (Spearman's $r=0.48$ ). Detailed, multiple regression analysis showed a significant effect on the FA of value of only one, the largest trait No. 1 (the width of half of the leaf plate) with the regression coefficient $b=0.1$ (PABG) and $b=1.1$ (GGTU); with a probability level of $p=0.01$. Metric traits turned out to be convenient for testing association between two types of variability - plastic and fluctuating (table 3 ).

Table 3. Correlation assosiation between PL and FA ( Spearman's $r$ )

\begin{tabular}{|c|c|c|c|c|c|c|c|c|c|c|c|}
\hline \multicolumn{9}{|c|}{ GGTU } & \multicolumn{7}{c|}{ PABG } \\
\hline & PL & 1 & 2 & 3 & 4 & 5 & 1 & 2 & 3 & 4 & 5 \\
\hline FA & & & & & & & & & & & \\
\hline 1 & & $0.75^{*}$ & -0.12 & 0.15 & -0.19 & -026 & 0.61 & $0.72^{*}$ & -0.42 & 0.26 & $0.81^{*}$ \\
\hline 2 & & -0.14 & 0.24 & $0.78^{*}$ & 0.37 & -0.22 & 0.39 & 0.56 & -0.33 & -0.24 & 0.49 \\
\hline 3 & & 0.31 & 0.09 & $0.78^{*}$ & 0.16 & 0.47 & -0.30 & 0.03 & 0.35 & $0.68^{*}$ & 0.14 \\
\hline 4 & & -0.24 & -0.58 & 0.50 & -0.07 & -0.15 & 0.07 & 0.38 & 0.04 & $0.82^{*}$ & 0.45 \\
\hline 5 & & -0.01 & 0.08 & -0.04 & 0.35 & $0.78^{*}$ & -0.16 & 0.02 & -0.27 & 0.15 & 0.31 \\
\hline
\end{tabular}

Note: ${ }^{*}-p<0.05$

A statistically significant correlation was obtained in four cases in each population $(16 \%)$. The strongest link (Spearman's $r=0.81-0.82$ ) was found in northern population. Thus the plastic variability, particularly in northern population, has been associated with the fluctuation variability.

\subsection{Geometric morphometrics of shape}

Set of values of the XY landmarks coordinates were converted into a consensus shape across the leaf blades, component of the size was removed, i.e., the Procrustes alignment was performed. Results of the Procrustes two-way analysis of variance revealed variability of the shape and asymmetry of leaf plates (table 4).

Table 4. Source of variation in Procrustes ANOVA

\begin{tabular}{|c|c|c|c|c|c|c|c|c|}
\hline \multicolumn{5}{|c|}{ GGTU } & \multicolumn{4}{|c|}{ PABG } \\
\hline Source & $S S$ & $M S$ & $d f$ & $F$ & $S S$ & $M S$ & $d f$ & $F$ \\
\hline Collection & 0.00 & 0.0001 & 50 & $0.42^{\mathrm{ns}}$ & 0.012 & 0.0002 & 50 & $10.87^{* *}$ \\
\hline Side & 0.01 & 0.0001 & 50 & $0.8^{\mathrm{ns}}$ & 0.022 & 0.0004 & 50 & $19.27^{* *}$ \\
\hline Collection $\times$ side & 0.01 & 0.0001 & 50 & $1.61^{*}$ & 0.001 & 0.0000 & 50 & $0.35^{\mathrm{ns}}$ \\
\hline Resudials & 1.79 & 0.0001 & 19800 & & 1.275 & 0.0001 & 19800 & \\
\hline Leaf & 0.696 & 0.0001 & 4950 & $0.64^{\mathrm{ns}}$ & 0.693 & 0.0001 & 4950 & $1.24^{* *}$ \\
\hline Side & 0.006 & 0.0001 & 50 & $0.53^{\mathrm{ns}}$ & 0.022 & 0.0004 & 50 & $3.81^{* *}$ \\
\hline Leaf $\times$ side & 1.084 & 0.0002 & 4950 & $92.29^{* *}$ & 0.559 & 0.0001 & 4950 & $31.7^{* *}$ \\
\hline Resudials & 0.024 & 0.0000 & 10000 & & 0.036 & 0.0000 & 10000 & \\
\hline
\end{tabular}


Notes: $S S$ - sum of squre; $d f$ - degree of fredom; $M S$ - mean squre; $F$ - Goodall's F criterion; ${ }^{*}-p<0.01$; $*_{*}-p<0.0001 ;$ ns - statistically no significant

Factor "collection" showed a difference in leaf shape (first row) only in the PABG population $(F=10.87 ; p<0.0001)$. Respectively, the whole set of leaf blades also differed in shape $(F=$ $1.24 ; p<0.0001)$.

Directional asymmetry ("side" factor) differed both among the two gathering of leaves ( $\mathrm{F}=$ 19.27; $p<0.0001)$ and whole set of leaves $(F=3.81 ; p<0.0001)$. Thus, in northern population, plastic variability, including variety in shape and size, correlated with fluctuating variability, which is typical for plants with a developing leaf blade and incomplete metabolic processes. In southern population, no differences in shape $(p>0.05)$ were found either in the sample collection or in all leaf blades. There was no directional asymmetry; therefore, the fluctuating asymmetry (interaction of both factors) was statistically significant $(1.61 ; p<0.01$ in collections; and $92.9 ; p<0.0001$ in all leaves).

The larger, better formed leaf blades showed higher FA. Small leaves of northern population with high values of directional asymmetry differed in shape. In comparison with the method of normalizing difference, which did not allow to evaluate differences in FA, the method of geometric morphometrics showed a clear presence of FA in southern population and its absence or weak presence in population on the Kola Peninsula (but with high directional asymmetry). The error of measuring leaf plates ("residuals") was $0.5-0.51 \%$ of the total sum of squares MS, which is considered acceptable when finding fluctuating asymmetry. Decomposition of the landmarks coordinates variance into the main components distinguished two main components of shape. They possessed more than $70 \%$ of the total variance and visually showed a difference in shape between the two populations (Fig. 1).

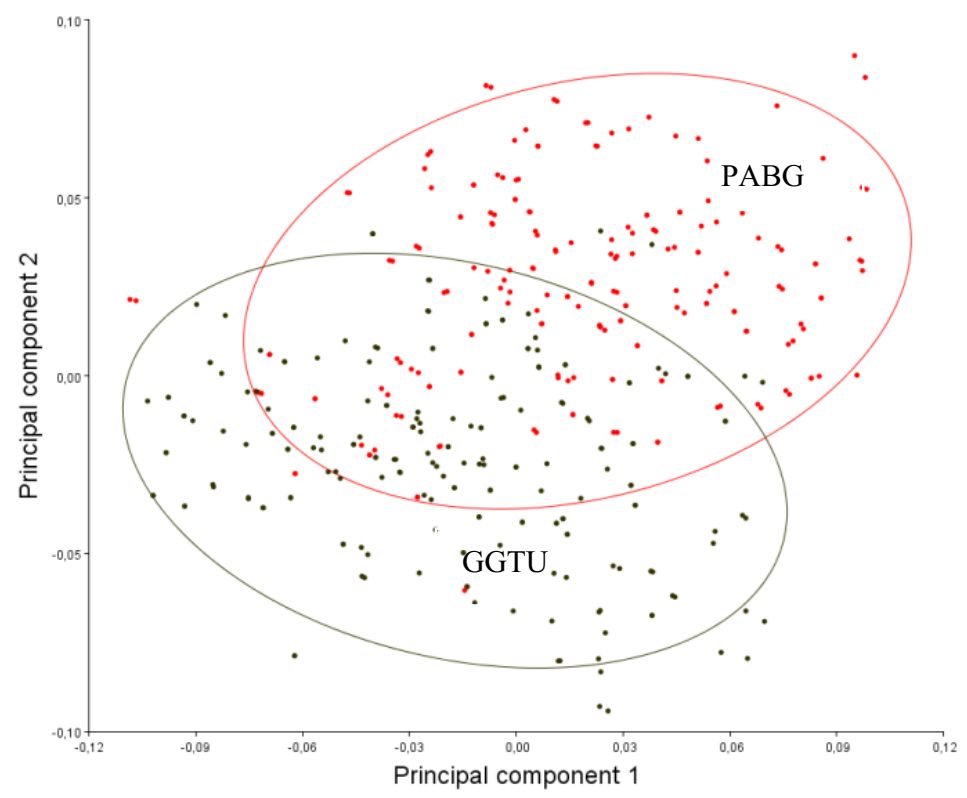

Fig.1. Two principal components of shape

The differences were quantitatively assessed in distances from center of consensus in the Procrustes distances (0.06) and in Mahalanobis distances (2.85) which revealed a statistically significant result $(\mathrm{p}<0.001)$. The asymmetry did not differ statistically; the sets were not divided into two ellipsoidal regions. Canonical principal component analysis showed the overlap of the two regions of the first components (fig. 2). 


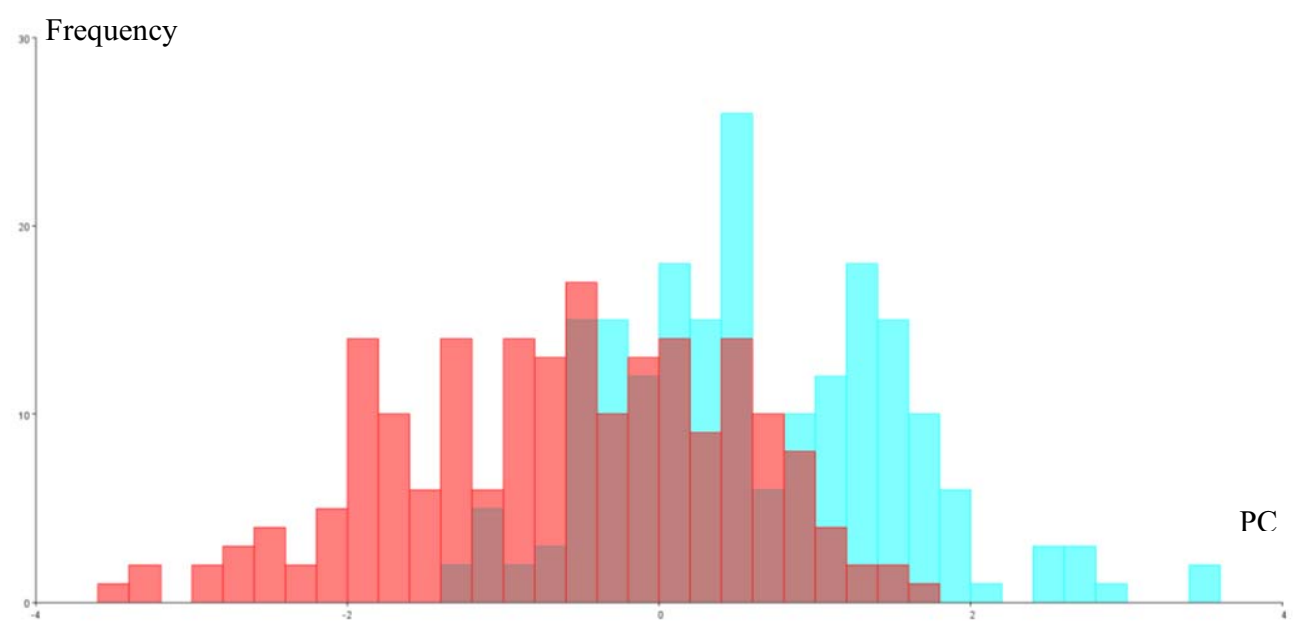

Fig.2. Two asymmetric components of shape (left - PABG, right - GGTU)

Asymmetric component of the shape included both directional and fluctuating asymmetry. Figure 2 shows a noticeably greater range frequency of asymmetry of the GGTU population. No regression relationship was obtained between magnitude of the consensus and the FA (as in the case of linear traits). Thus, no allometric variability of asymmetry was obtained depending on size of leaf blades. Small leaf size in northern population was associated with directional asymmetry. We consider the asymmetry of shape as a specific approach to the developmental stability study.

The first feature (the width of leaf blades half) often serves to determine the developmental stability, can be used when comparing leaf blades of the same size, while for different dimensional characteristics, method of geometric morphometry should be used. The developmental stability in the southern population was the same $(\mathrm{FA}=0.027)$ as in previous years in 2014-2017 (trait №1 FA =0.026-0.031). At the same time, there is a study on directional asymmetry as an indicator of a stress factor that reduces developmental stability [18]. In our opinion, if there is no relationship "FA - leaf size", then FA should be compared, for example, by the value of MS of the "leaf $\times$ side" interaction. Directional asymmetry is more likely a genetically determined adaptive property, for example, as in our case, to adverse climatic environment and slow development with extending in phenophases.

\section{Conclusions}

a. Geometric morphometrics allows testing the variability of both shape and asymmetry of leaf blade and can be used for samples of blades of different sizes.

b. The introduced (northern) population of Tilia cordata Mill. characterized by smaller value of leaf plates and significant directional asymmetry, in contrast to the population in the central part of the areal extent with high fluctuating asymmetry, without directional asymmetry. No difference in overall asymmetry was obtained by the method of geometric morphometrics. Shape turned out to be a more contrasting characteristic.

c. In northern population, shape of leaf blades differed even between the two collections, which, however, did not cause a decrease in developmental stability, assessed by FA. High directional asymmetry deserves a separate study. Thus, the hypothesis about the influence of climate on shape and peculiarities of asymmetry in leaf blades of small-leaved linden has been confirmed. 


\section{References}

1. L.G. Martynov, Izvestiya Komi Scientific Center URO RAS, 3 (19). (2014)

2. L. Li., X. Wang, W.J. Manning, Frontiers in plant science, 10. (2019) doi.org/10.3389/fpls.2019.01217

3. E.A. Erofeeva, Dose Response 13, 1-6. (2015), doi.org/10.1177\%2F1559325815588510

4. K. Kramer, Plant Cell and Environment, 18, 93-104. (1995) doi.org/10.1111/j.13653040.1995.tb00356.x

5. Y. Vitasse, C. Bresson, A. Kremer, R. Michalet, S. Delzon Functional Ecology, 24, 1211 1218. (2010). doi.org/10.1111/j.1365-2435.2010.01748.x

6. S. Acuna-Rodriguez, C. Torres-Diaz, R. Hereme, M.A. Molina-Montenegro, PeerJ, 5, e3718. (2017). https://www.ncbi.nlm.nih.gov/pubmed/28948096

7. D.V. de Morais, L.A Nunes, V.P. da Mata, M.A. P. de Carvalho Costa, G. da Silva Sodre, C.A.L. de Carvalho, Bioscience Journal, 35(6). (2019). http://orcid.org/0000-0002-27377428

8. S.N. Sheth, N. Morueta Holme, A.L. Angert, New Phytologist, 226(3), 650-665. (2020). https://doi.org/10.1111/nph.16406

9. S.V. Migalina, L.A. Ivanova, A.K. Makhnev, Russian Journal Plant Physiol, 56(6), 858. (2009). https://link.springer.com/article/10.1134/S102144370906017X\#citeas

10. V.M. Zakharov, N.G. Kryazheva, S.G. Dmitriev, I.E. Trofimov, Biology Bull Rev, 2(2), 190-193. (2012) https://link.springer.com/article/10.1134/S2079086412020107\#citeas

11. E.G. Shadrina, Y.L. Vol'pert, Russ J Dev Biol, 45(3), 117-126. (2014) https://link.springer.com/article/10.1134/S1062360414030059\#citeas

12. M.V. Kozlov, V. Zverev, Russia. Sci. Total Environ., 640-641, 678-687. (2018) https://doi.org/10.1016/j.scitotenv.2018.05.328

13. V. Zverev, M.V. Kozlov, Symmetry, 12, 1703. (2020) https://doi.org/10.3390/sym12101703

14. I.E. Zykov, L.V. Fedorova, S.G. Baranov, Bull Moscow State Reg Univ. Ser. Natural Sciences, 1:15-21. (2015)

15. S.G. Baranov, I.E. Zykov L.V. Fedorova,Vestnik Tomskogo Gos Univers. Biologiya. 2 (30), 134-145. (2015) https://cyberleninka.ru/article/n/vliyanie-klimaticheskogo-faktora-naplastichnost-i-asimmetriyu-listovyh-plastin-predstaviteley-roda-tilia-l (дата обращения: 27.01.2021)

16. S. Baranov, I. Zykov, L. Fedorova, Principy èkologii. 8(1), 3-18. (2019)

17. S.G. Baranov, Advan. Environ. Biol., 8, 2391-2398. (2014) http://www.aensiweb.com/aeb.html

18. E.A. Erofeeva, B.N. Yakimov, Symmetry, 12(5), 727. (2020) https://doi.org/10.3390/sym12050727

19. S.G. Baranov, I.E. Zykov, D.D. Kuznetsova, Vavilov J of Genet and Breed, 23, 496-02. (2019) doi 10.18699/VJ19.519

20. S.G. Baranov, I.Y. Vinokurov, I.E. Zykov, L.V. Fedorova, In IOP Conf. Ser.: Earth Environ. Sci. 548 (7), 072015). IOP Publishing. (2020, August) doi:10.1088/1755$1315 / 548 / 7 / 072015$

21. S.G. Baranov, I.E. Zykov, D.D. Kuznetsova, A.M. Antsyshkina, L.V. Fedorova, In IOP Conf. Ser.: Earth Environ.Sci. 548(3), 032001. IOP Publishing.). (2020, August).https://doi:10.1088/1755-1315/548/3/032001 